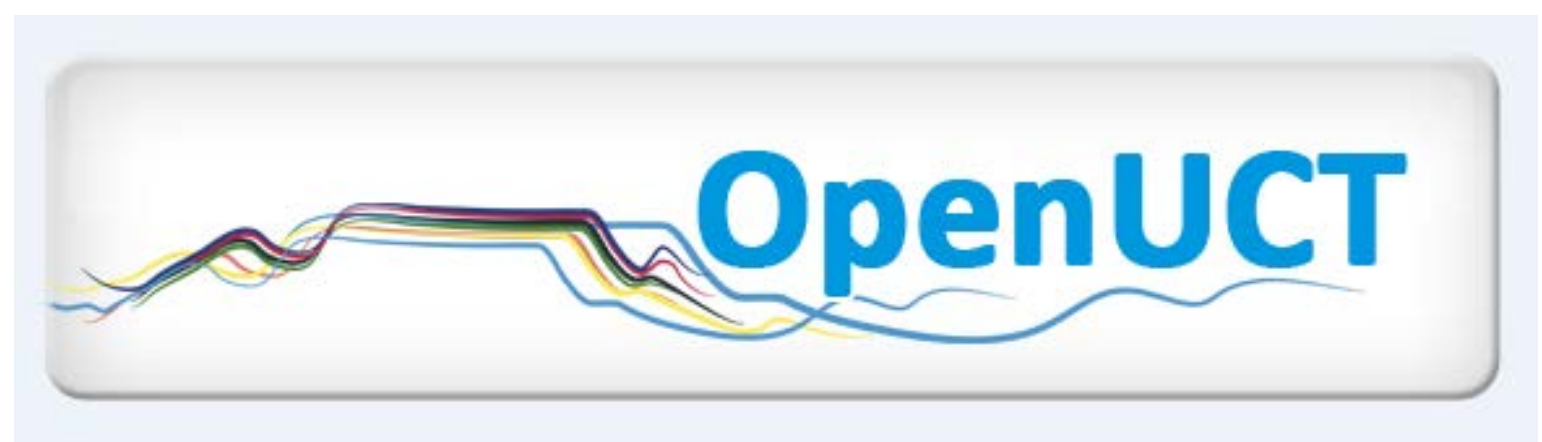

This is the post-print of Van Pletzen, E., Stein, D. J., Seedat, S., Williams, D. R. \& Myer, L. 2012. Recall of early non-fatal suicidality in a nationally representative sample of South Africans. Ethnicity \& Health. 17(1-2): 149-159. DOI: 10.1080/13557858.2012.664271.

It is made available according to the terms of agreement between the author and the journal, and in accordance with UCT's open access policy available:

http://www.openuct.uct.ac.za/sites/default/files/UCTOpenAccessPolicy.pdf, for the purposes of research, teaching and private study. 
E-mail: ermien.vanpletzen@uct.ac.za

\title{
Recall of early non-fatal suicidality in a nationally representative sample of South Africans
}

\author{
a-Ermien van Pletzen, b-Dan J. Stein, c-Soraya Seedat, d, e-David R. Williams and \\ f, g-Landon Myer \\ a-Centre for Higher Education Development, University of Cape Town, Cape Town, South Africa; \\ b-Department of Psychiatry and Mental Health, University of Cape Town, Cape Town, \\ South Africa; \\ c-Department of Psychiatry, Faculty of Health Sciences, Stellenbosch University, Tygerberg campus, Cape Town, South \\ Africa; \\ d-Department of Society, Human Development and Health, Harvard School of Public Health, Boston, MA, USA; e- \\ Department of African and African American Studies, Harvard University, Cambridge, MA, USA; \\ f-School of Public Health and Family Medicine, University of Cape Town, Cape Town, South Africa; g-Department of \\ Epidemiology, Mailman School of Public Health, Columbia University, New York, USA
}

\begin{abstract}
Objectives. Little is known about socio-demographic patterns of non-fatal suicidality in early life in South Africa. We investigated the prevalence of self reported early suicidality (suicidal ideation, planning and attempts) in a nationally-representative sample of South Africans. Design. As part of a larger mental health survey, 3158 individuals aged over 25 years were asked to recall whether they engaged in non-fatal suicidal behaviour in early life (measured from childhood to 25 years). Race-based discrimination institutionalised under Apartheid profoundly influenced delivery and outcomes in health and other social services. Racial categories entrenched during Apartheid were therefore used to analyse data collected from individuals born before 1946, 1947-1956, 1957-1966 and 1967-1976. Results. 3.4\% (95\% CI=2.6-4.1) of participants recalled early suicidal behaviour. The youngest group (born 1967-1976) recalled higher rates of early suicidality than older groups in all races. In unadjusted analysis White people were 2.84 (95\% CI=1.624.97) and Coloured people $1.84(95 \%$ CI=1.15-2.93) times more likely than Black people to recall early suicidality. Individuals growing up in urban and higher socioeconomic settings were approximately twice
\end{abstract}


E-mail: ermien.vanpletzen@uct.ac.za

$(O R=2.2 ; 95 \% C I=1.14-4.28$ and $O R=1.92 ; 95 \% C I=1.27-2.90)$ as likely to recall early suicidality as those growing up in rural and lower socioeconomic settings. Those with post-primary education were 2.79 (CI=1.71-4.53) times as likely to recall early suicidality as those with none or only primary education. Racial differences ceased to be significant after adjustment for rural/urban location and other socioeconomic measures estimated for early life. Conclusion. The study provides novel evidence of increasing levels of early non-fatal suicidality recalled by younger South Africans. Levels appeared significantly higher in Whites than in Blacks. Socioeconomic contexts in early life were interpreted as mediators rather than confounders of the association between race and recalled early suicidality. The findings for decreased levels of suicidality among participants growing up in lower socioeconomic strata and rural settings in South Africa require further investigation. The need for wide-spread suicide prevention programmes targeting young people at a population level is emphasised.

Keywords: early non-fatal suicidality, suicidal behaviour, race, South Africa, youth 


\section{Key points}

What is known about this topic

Non-fatal suicidal behaviour is increasingly recognised as a serious public health problem.

Few data exist on non-fatal suicidality, especially among different ethnic groups in developing countries and specifically in South Africa with its racially segregated past.

There are indications of an increase in non-fatal suicidal behaviour among young people.

What the paper adds

White South Africans across all age groups are more likely than Black and Coloured people to recall engaging in non-fatal suicidal behaviour before the age of 25 .

South Africans across all race groups born between 1967 and 1976 are more likely to recall engaging in early non-fatal suicidal behaviour than people born before 1967. Individuals growing up in urban and higher socioeconomic settings were approximately twice as likely to recall early suicidality as those growing up in rural and lower socioeconomic settings. 
E-mail: ermien.vanpletzen@uct.ac.za

\section{Introduction}

Non-fatal suicidality is increasingly recognised as a serious public health problem causing widespread emotional and physical suffering, disability and adverse economic consequences (Kapur et al. 2006). Despite worldwide concern about suicidality, there are few robust data on suicide in African populations. In South Africa, there are few data on suicide in non-white populations marginalised under Apartheid (Flisher et al. 2004) and almost no systematic data on non-fatal suicidality. Schlebusch (2005) estimates that between 137,860 and 160,000 South Africans engage in non-fatal suicidal behaviour per year. Reporting for the first time on nationally representative data from the South African Stress and Health study, Joe et al. (2008a, 2008b) found a lifetime prevalence of 9.1\% for reported suicidal ideation, 3.8\% for planning, and 2.9\% for suicide attempts, with important variation among race groups and the highest risk of attempted suicide among young people. Given the increase in suicidal behaviour commonly reported among young people (Diekstra et al. 1995, WHO SUPRE 2007), we analyse the same data here, focusing however not on life-time suicidality, but on recall of early life non-fatal suicidal behaviour, defined in our study as recall of suicidal ideation, planning or attempts up to the age of 25 years. We examine the prevalence of recall of early suicidality in South Africans in different race groups and different years of birth (those born before 1946; 1947-1956; 1957-1966; and 1967-1976).

\section{Methods}

The South African Stress and Health study is a national cross-sectional survey of mental health conducted between January 2002 and June 2004 (Williams et al. 2004). A three- 
E-mail: ermien.vanpletzen@uct.ac.za

stage probability sample design was used to select a sample of 4351 South African adults. The interview instrument, the Composite International Diagnostic Interview (WMH-CIDI, WHO 1997), was available in seven national languages. The overall response rate was 85.5\%. No ethnically differentiated response rates were available. Participants were asked to recall whether they engaged in any form of non-fatal suicidal behaviour in early life (ideation, planning or attempts). Since recall of non-fatal suicidal behaviour up to the age of 25 was examined, only participants at least 26 years old at the time of the study were included ( $\mathrm{n}=3158)$.

Participants were asked to self-identify with one of four racial categories: Black (African), Coloured (mixed race), White and Indian/Other (general Asian grouping). These are crude racial categories not reflective of nuanced ethnic identification, but we are constrained to using them because of their presence in racially discriminatory Apartheidera policies, and because they are still widely used in South African research to indicate historical disadvantage and for purposes of redress.

We established participants’ year of birth using their age and the date of the interview. Since participants were asked to recall whether they had engaged in suicidal behaviour during early life, we included three estimates of socioeconomic context during early life in analysis: (i) the location (rural/urban) where participants spent their childhood and adolescence ('early location’); (ii) participants' socioeconomic position during childhood and adolescence ('early socioeconomic position’) based on parental education and occupation; and (3) participants' own level of education. We further included measures of adult socioeconomic context linked to participants' socioeconomic situation at the time of the interview: (1) their location (rural/urban) at the time of the interview ('adult location') and (2) their family income at the time of the interview. Since the study includes 
E-mail: ermien.vanpletzen@uct.ac.za

participants born at different historical times (from the early to late twentieth century), broad and stable binary measures were constructed to accommodate possible socioeconomic shifts over time, as well as possible shifts in the value associated with levels of education and occupation over time. Parental education levels were categorised around the median, while participants' education was categorised very broadly as 'None or primary education’ versus ‘Post-primary education’. Parental occupation was divided into unskilled manual labour versus any skilled work, while family income at the time of the interview was categorised as below R100,000 and from R100,000.

Data were analysed using Stata Version 9.0 (Stata Corporation, College Station, USA). All analyses accounted for the complex survey design based on person-level weights that incorporated sample selection, non-response and post-stratification factors. Domain analyses were used in analysing sub-sets of the sample. Descriptive statistics using univariate and bivariate methods were generated for all variables. Multiple logistic regression models were constructed to assess the independent association between early non-fatal suicidality, race and year of birth.

\section{Results}

[refer to tables $1 \& 2$ pages $16 \& 17]$

Overall, 3.4\% (95\% CI=2.6\%-4.1\%) of participants recalled early life suicidality. The proportion was highest among Whites at 7.1\% (95\% CI=4.2\%-10.0\%) and highest at 5.4\% (95\% CI=3.9\%-6.8\%) in the youngest group, born 1967-1976 (Table 1).

In unadjusted analysis, White people were 2.84 (95\% CI=1.62-4.97) times and Coloured people 1.84 (95\% CI=1.15-2.93) times as likely as Black people to recall early suicidality (Tables 1 and 2). Compared with the youngest participants (born 1967-1976), the second youngest (born 1957-1966) were 46\% (95\% CI=0.30-1.05), the second oldest 
E-mail: ermien.vanpletzen@uct.ac.za

(born 1947-1956) 83\% (95\% CI=0.08-0.34), and the oldest (born before 1946) 59\% (95\% $\mathrm{CI}=0.21-0.81$ ) less likely to recall early suicidality (Table 2 ). Individuals growing up in urban settings and in households with higher socioeconomic status were approximately twice (OR=2.2; 95\% $\mathrm{CI}=1.14-4.28$ and $\mathrm{OR}=1.92 ; 95 \% \mathrm{CI}=1.27-2.90)$ as likely as those growing up in rural settings and households with lower socioeconomic status to recall early suicidality (Table 2). Those with post-primary education were 2.79 (CI=1.71-4.53) times as likely to recall early suicidality as those with none or only primary education.

In multivariate analysis, the association between recalled non-fatal suicidality, race and year of birth persisted (Table 2, Model B). When early life socioeconomic variables were added separately to this model, the racial association with reported early suicidality was attenuated in each case (results not shown). When all three early socioeconomic variables were added together to the model, the racial association ceased to be significant, while the association between recall of early non-fatal suicidality and year of birth persisted (Table 2, Model C). The association between recall of non-fatal suicidality, race and year of birth persisted when adjusted for the adult socioeconomic variable (family income at time of the interview), therefore ruling out the possibility that adult socioeconomic status at the time of recall confounded the racial association with early suicidality (Table 2, Model D). Adult rural/urban location had no effect on the racial association (results not shown).

\section{Discussion}

The study provides novel evidence of significantly higher levels of recall of early non-fatal suicidality in White people compared to other race groups in South Africa, and increased levels in the youngest group, born from 1967 to 1976. While our study reports on 
participants' recall of suicidal behaviour rather than forms of evidence like hospital admissions, we consider recall as a crude proxy for engaging in suicidal behaviour.

The crude association between recall of early suicidality and race disappeared when adjusted for socio-demographic contexts in early life, raising the possibility that race is not independently associated with recall of suicidality but confounded by these variables. Kaufman and Cooper (2001) point out, however, that in racially stratified societies almost all potential covariates in an analysis treating race as an exposure are causal intermediaries rather than confounders. Since covariates like socioeconomic status, geographic location and education were (and to a large extent still are) profoundly influenced by race in a country like South Africa, adjusting for them as confounders could lead to overadjustment (Kaufman and Cooper 2001). These variables may be mediators rather than confounders and offer explanation of potential pathways through which race, as a social, discriminatory construct, may affect recall of early non-fatal suicidality.

Studies have found positive association between suicidal behaviour and low socioeconomic position (Vijayakumar et al. 2005, Beautrais et al. 2006), rural location (Hirsch 2006) and low educational attainment (Beautrais et al. 2006). A wholly different situation presents itself in our study, in that being Black, having been raised in a household with a low socioeconomic position or in a rural location, and having little education surprisingly led to less self-report of early suicidality. A possible explanation is that these socio-demographic variables could be proxies for forms of social cohesion and social integration that occurred more readily in rural, traditional Black communities in South Africa and that may lower recall of suicidality among Black people or may affect their engagement in early suicidality. Several South African studies have pointed to the effect 
of social cohesion and integration on psychological distress and suicidal behaviour (Madu and Matla 2003, Myer et al. 2008, Wild et al. 2004).

Moreover, race is a proxy for a wide range of cultural practices and belief systems that may affect suicidal behaviour or recall of suicidal behaviour differentially. Mental health conditions are closely linked with linguistic and other forms of cultural or ethnic conceptualisation, which could have an effect on how such conditions manifest themselves, are interpreted, diagnosed and treated in different geographic locations and among different ethnic groupings (Swartz 1998). Strong traditional cultural belief systems, such as those found in predominantly rural Black communities in South Africa, may involve strong proscription of suicidal behaviour or may strengthen social networks and a sense of integration, both of which may affect suicidal behaviour or recall of suicidal behaviour, explaining the higher prevalence of recall among White people. These structures may however also increase stigma around suicidal behaviour, which could lead to under diagnosis or under reporting (Swartz 1998).

A third possible explanation for higher rates of recall of non-fatal suicidality among White people is that the political climate in South Africa during the mid to late 20th century further differentiated people’s experiences along racial lines. Increasingly oppressive Apartheid policies led to greater collective struggle, solidarity, sense of purpose and desire for change among young Black, Coloured, Indian and a minority of White people as the liberation struggle gained momentum, whereas the experience for the vast majority of White South Africans was one of increasing political isolation and fear of losing socioeconomic privilege (Terreblanche 2002). Burrows et al. (2003, citing Henry and Short 1954, Lester 1984 and 1989) argue that people suffering political and economic disadvantage in Apartheid South Africa may have had an external source of blame which 
made them more likely to direct violence outwards, towards the source of oppression, while those without such an external source of blame (White people privileged by Apartheid) may have tended to blame themselves for problems in their lives and direct violence inwards, against themselves.

The rise in recall of early suicidality among younger individuals of all races (Table 1) could also be understood socially. Increased urbanization beginning in the 1980s, especially among Black people (Terreblanche 2002, Seekings and Nattrass 2005), might have weakened forms of social cohesion and integration protective against suicidality. The political transition in 1994 may furthermore have engendered a sense of decreased solidarity and failed aspiration among the previously disadvantaged and increased isolation and fear of losing privilege among the previously advantaged (Terreblanche 2002, Seekings and Nattrass 2005). The appearance of HIV/AIDS in the late 1980s and the development of a large-scale epidemic with devastating social consequences by the late 1990s in South Africa may further have contributed to an increase in mental disorders, stress, isolation and hopelessness, which could drive up suicidal behaviour (Myer et al. 2009).

Our results should be interpreted in light of several limitations. Race was reduced to fixed categories that reflect neither the complexity nor the contested nature of ethnic constructs in a country like South Africa where a legacy of crude racial segregation is in conflict with a nascent democratic society comprising multiple ethnicities and languages. Second, small sample sizes in especially the older groups make estimates imprecise and rule out conclusions about recall of suicidality in these groups. Third, survival bias is a major limitation of our analyses. Each birth-year group is affected by survival bias, and this bias could be larger in the older groups. A difference in recall of suicidal behaviour 
E-mail: ermien.vanpletzen@uct.ac.za

between an older and younger group could therefore be due to either a true difference or to a survival effect. Fourth, recall of suicidal behaviour was treated as a crude proxy for suicidal behaviour, which raises further limitations. Differential recall bias is a serious limitation in that older participants were further removed from the experience of early non-fatal suicidality and they may therefore recall the outcome differently from younger participants. Moreover, despite the availability of the interview instrument in several national languages, understandings and perceptions of suicidality could have varied among cultural, ethnic and age groups, potentially affecting recall of suicidality and giving rise to further forms of differential information bias.

Despite these shortcomings, our paper makes an important contribution given the scarcity of data on non-fatal suicidal behaviour in South Africa and the almost complete absence of data among ethnic groups other than White in the twentieth century. The findings that there is less recall of non-fatal suicidality in lower socioeconomic strata and rural settings in South Africa require further investigation. The potential effect of social cohesion and integration on suicidality despite adversity and racial discrimination require further research. Variation in cultural understanding and conceptualisation of suicidality also needs to be investigated in order to improve diagnosis and minimize differential information bias in self-reported data. The overall increase in recall of early non-fatal suicidality in the youngest groups is a cause for concern and points to the need for further research, as well as appropriate suicide prevention programmes that target young people living in complex multi-ethnic societies.

Acknowledgements: The South African Stress and Health Study was carried out in conjunction with the World Health Organization World Mental Health (WMH) Survey 
E-mail: ermien.vanpletzen@uct.ac.za

Initiative. We thank the WMH staff for assistance with instrumentation, fieldwork and data analysis.

Funding: Supported by the United States National Institute of Mental Health (R01MH070884), the John D. and Catherine T. MacArthur Foundation, the Pfizer Foundation, the US Public Health Service (R13-MH066849, R01-MH069864 and R01DA016558), the Fogarty International Center (FIRCA R01-TW006481), the Pan American Health Organization, Eli Lilly and Company, Ortho-McNeil Pharmaceutical, Inc., GlaxoSmithKline and Bristol-Myers Squibb. The South African Stress and Health Study was funded by grant R01-MH059575 from the National Institute of Mental Health and the National Institute of Drug Abuse, with supplemental funding from the South African Department of Health and the University of Michigan. D. Stein and S. Seedat are also supported by the Medical Research Council of South Africa.

\section{References}

Beautrais, A.L., Wells, J.E., McGee, M.A., and Oakley Browne, M.A., 2006. Suicidal behaviour in Te Rau Hinengaro: The New Zealand Mental Health Survey. Australian and New Zealand Journal of Psychiatry, 40, 896-904.

Burrows, S., Vaez, M., Butchart, A., and Laflamme, L., 2003. The share of suicide in injury deaths in the South African context: Socio-demographic distribution. Public Health, 117, 3-10.

Diekstra, R.F.W., Kienhorst, C.W.M., and De Wilde, E.J., 1995. Suicide and suicidal behaviour among adolescents. In: M. Rutter, \& D.J. Smith, eds. Psychosocial disorders in young people. Chichester: John Wiley \& Sons, 686-761. 
Flisher, A., Liang, H., Laubscher, R., and Lombard, C.F., 2004. Suicide trends in South Africa, 1968-90. Scandinavian Journal of Public Health, 32, 411-418.

Henry, A.F. and Short, J., 1954. Suicide and homicide: some economic, sociological and psychological aspects of aggression. Glencoe, IL: Free Press.

Hirsch, J. K., 2006. A review of the literature on rural suicide: risk and protective factors, incidence and prevention. Crisis, 27(4), 189-199.

Joe, S., Stein, D. J., Seedat, S., Herman, A., and Williams, D. R., 2008a. Prevalence and correlates of non-fatal suicidal behaviour among South Africans. British Journal of Psychiatry, 192(4), 310-311.

Joe, S., Stein, D. J., Seedat, S., Herman, A., and Williams, D. R., 2008b. Non-fatal suicidal behavior among South Africans. Social Psychiatry and Psychiatric Epidemiology, 43(6), 454-461.

Kapur, N., Cooper, J., King-Hele, S., Webb, R., Lawlor, M., Rodway, C. et al. 2006. The repetition of suicidal behavior: a multicentre cohort study. Journal of Clinical Psychiatry, 67(10), 1599-1609.

Kaufman, J.S. and Cooper, R.S., 2001. Commentary: Considerations for use of racial/ethnic classification in etiologic research. American Journal of Epidemiology, 154(4), 291-297.

Lester, D., 1984. The association between the quality of life and suicide and homicide rates. Journal of Social Psychology, 124, 247-248.

Lester, D., 1989. Personal violence (suicide and homicide) in South Africa. Acta Psychiatrica Scandenavica, 79, 235-237. 
Madu, S.N. and Matla, M.P., 2003. The prevalence of suicidal behaviours among secondary school adolescents in the Limpopo Province, South Africa. South African Journal of Psychology, 33(2), 126-132.

Myer, L., Seedat, S., Stein, D.J., Moomal, H., and Williams, D.R., 2009. The mental health impact of AIDS-related mortality in South Africa: a national study. Journal of Epidemiology and Community Health, 63, 293-298.

Myer L, Stein D.J., Grimsrud A., Seedat S., and Williams D.R., 2008. Social determinants of psychological distress in a nationally-representative sample of South African adults. Social Science and Medicine, 66(8), 1828-40.

Schlebusch, L., 2005. Suicidal Behaviour in South Africa. Scotsville: University of KwaZulu-Natal Press.

Seekings, J. and Nattrass, N., 2005. Class, Race, and Inequality in South Africa. Scottsville: University of KwaZulu-Natal Press.Terreblanche S., 2002. A History of Inequality in South Africa, 1652-2002. Scottsville: University of Natal Press.

Swartz, L., 1998. Culture and Mental Health: a Southern African view. Cape Town: Oxford University Press.

Terreblanche, S., 2002. A History of Inequality in South Africa, 1652-2002. Scottsville: University of Natal Press.

Vijayakumar, L., John, S., Pirkis, J., and Whiteford, H., 2005. Suicide in developing countries (2): Risk factors. Crisis, 26(3), 112-119.

Wild, L.G., Flisher, A.J., and Lombard, C., 2004. Suicidal ideation and attempts in adolescents: associations with depression and six domains of self-esteem. Journal of Adolescence, 27, 611-624. 
E-mail: ermien.vanpletzen@uct.ac.za

Williams, D.R., Herman, A., Kessler, R.C., Sonnega, J., Seedat, S., Stein, D.J., Moomal, H. \& Wilson, C.M. 2004. The South Africa Stress and Health Study: rationale and design. Metabolic Brain Disease, 19(1-2), 135-47.

World Health Organization, 2010. Suicide Prevention Programme (SUPRE) Available from: http://www.who.int/mental_health/prevention/suicide/suicideprevent/en/ [Accessed 10 August 2010]. 
Table 1.

Crude association between recalled early non-fatal suicidality and race; proportion and absolute (unweighted) number of participants recalling early non-fatal suicidality by year of birth

\begin{tabular}{|c|c|c|c|c|c|c|c|c|c|c|c|}
\hline & \multirow{2}{*}{$\begin{array}{l}\text { Crude association } \\
\text { with recalled } \\
\text { early non-fatal } \\
\text { suicidality }\end{array}$} & \multicolumn{7}{|c|}{$\begin{array}{l}\text { Proportion and absolute (unweighted) number of participants recalling early non-fatal suicidality by } \\
\text { year of birth }\end{array}$} & \multirow{3}{*}{$\begin{array}{l}\text { Total \% } \\
\%(95 \% \mathrm{CI}) \\
\end{array}$} & \multirow{2}{*}{\multicolumn{2}{|c|}{ Total $\mathrm{n} / \mathrm{N}$}} \\
\hline & & $1967-1976$ & \multicolumn{2}{|c|}{$1957-1966$} & \multicolumn{2}{|c|}{$1947-1956$} & \multicolumn{2}{|c|}{$<1947$} & & & \\
\hline & OR $\quad(95 \% \mathrm{CI})$ & $\%(95 \% \mathrm{CI})$ & $\%(95 \% \mathrm{CI})$ & $\mathrm{n} / \mathrm{N}$ & $\%(95 \% \mathrm{CI})$ & $\mathrm{n} / \mathrm{N}$ & $\%(95 \% \mathrm{CI})$ & $\mathrm{n} / \mathrm{N}$ & & & \\
\hline \multirow{4}{*}{$\begin{array}{l}\text { Black } \\
\text { Coloured } \\
\text { White } \\
\text { Asian }\end{array}$} & 1.0 & $4.5(2.9-6.1) \quad 39927$ & $2.2(0.5-3.9)$ & 13627 & $0.6(0-1.1)$ & $4 \quad 416$ & $1.2(0-2.8)$ & 3368 & $2.6(1.8-3.4)$ & 59 & 2338 \\
\hline & $1.84 *(1.15-2.93)$ & $6.8(1.7-11.9) \quad 9 \quad 150$ & $4.3(1.7-7.0)$ & $7 \quad 116$ & $3.2(0.7-5.7)$ & 96 & $2.8(0-7.7)$ & 86 & $4.7(3.0-6.4)$ & 20 & 448 \\
\hline & $2.84 *(1.62-4.97)$ & $13.2(7.7-18.7) 8$ & $6.5(1.1-11.8)$ & 72 & No observation & 40 & $6.6(0-14.5)$ & 68 & $7.1(4.2-10.0)$ & 14 & 248 \\
\hline & $1.26 *(0.54-2.96)$ & $4.4(1.8-7.1) \quad 3 \quad 54$ & $3.3(0-8.2)$ & 235 & $3.1(0-9.2)$ & 20 & No observation & 15 & $3.3(0.8-5.8)$ & 6 & 124 \\
\hline Total & & $5.4(3.9-6.8)$ & $3.1(1.6-4.6)$ & 26850 & $0.9(0.4-1.5)$ & 572 & $2.3(0.8-3.8)$ & 537 & $3.4(2.6-4.1)$ & 99 & 3158 \\
\hline
\end{tabular}

*Statistically significant 
Table 2.

Associations between recalled early non-fatal suicidality, race, and other socio-demographic variables in early and adult life

\begin{tabular}{|c|c|c|c|c|c|c|c|c|}
\hline \multirow{3}{*}{ Race } & \multicolumn{2}{|c|}{ Model A } & \multicolumn{2}{|c|}{ Model B } & \multirow{2}{*}{\multicolumn{2}{|c|}{$\begin{array}{l}\text { Model C } \\
\text { OR 95\% CI }\end{array}$}} & \multicolumn{2}{|c|}{ Model D } \\
\hline & \multirow[t]{2}{*}{ OR } & \multirow[t]{2}{*}{$95 \% \mathrm{CI}$} & \multirow[t]{2}{*}{ OR } & \multirow[t]{2}{*}{$95 \%$ CI } & & & \multirow[t]{2}{*}{ OR } & \multirow[t]{2}{*}{$95 \%$ CI } \\
\hline & & & & & & & & \\
\hline Black & 1.0 & & 1.0 & & 1.0 & & 1.0 & \\
\hline Coloured & $1.84 *$ & $1.15-2.93$ & $1.94 *$ & $1.18-3.19$ & 1.46 & $(0.78-2.76)$ & $1.99 *$ & $(1.22-3.23)$ \\
\hline White & $2.84 *$ & $1.62-4.97$ & $3.30^{*}$ & $1.85-5.90$ & 2.22 & $(0.99-5.0)$ & $3.86^{*}$ & $(2.17-6.86)$ \\
\hline Indian/other & 1.26 & $0.54-2.96$ & 1.26 & $0.52-3.06$ & 0.85 & $(0.30-2.39)$ & 1.38 & $(0.57-3.34)$ \\
\hline \multicolumn{9}{|l|}{ Year of birth } \\
\hline $1967-1976$ & 1.0 & & & & & & 1.0 & \\
\hline 1957-1966 & 0.56 & $0.30-1.05$ & $0.50 *$ & $0.27-0.90$ & $0.52 *$ & $(0.29-0.94)$ & $0.52 *$ & $(0.28-0.94)$ \\
\hline $1947-1956$ & $0.17 *$ & $0.08-0.34$ & $0.16^{*}$ & $0.08-0.32$ & $0.17 *$ & $(0.0 .08-0.36)$ & $0.15^{*}$ & $(0.07-0.32)$ \\
\hline$<1947$ & $0.41^{*}$ & $0.21-0.81$ & $0.35 *$ & $0.20-0.61$ & $0.43^{*}$ & $(0.23-0.80)$ & $0.34 *$ & $(0.19-0.62)$ \\
\hline \multicolumn{9}{|l|}{ Sex } \\
\hline Male & 1.0 & & & & & & & \\
\hline Female & 0.92 & 0.51-1.65 & & & & & & \\
\hline \multicolumn{9}{|l|}{ Early location } \\
\hline Rural & 1.0 & & & & 1.0 & & & \\
\hline Urban & $2.2^{*}$ & $1.14-4.28$ & & & 1.61 & $(0.66-3.91)$ & & \\
\hline \multicolumn{9}{|l|}{ Adult location } \\
\hline Rural & 1.0 & & & & & & & \\
\hline Urban & $1.79 *$ & $0.99-3.23$ & & & & & & \\
\hline \multicolumn{9}{|c|}{$\begin{array}{l}\text { Early socioeconomic } \\
\text { position }\end{array}$} \\
\hline Low & 1.0 & & & & 1.0 & & & \\
\hline High & $1.92 *$ & $1.27-2.90$ & & & 1.19 & $(0.74-1.92)$ & & \\
\hline \multicolumn{9}{|c|}{ Adult family income } \\
\hline$<\mathrm{R} 100,000$ & 1.0 & & & & & & 1.0 & \\
\hline R100,000 + & 0.47 & $0.21-1.05$ & & & & & $0.38 *$ & $(0.17-0.89)$ \\
\hline \multicolumn{9}{|l|}{ Education } \\
\hline None or primary & 1.0 & & & & 1.0 & & & \\
\hline Post-primary & $2.79 *$ & $1.71-4.53$ & & & 1.47 & $0.81-2.67$ & & \\
\hline
\end{tabular}

Model A: Crude association between recalled early non-fatal suicidality and socio-demographic variables

Model B: Association between recalled early non-fatal suicidality, race and year of birth

Model C: Association between recalled early non-fatal suicidality, race and year of birth, adjusted for early location, early socioeconomic position and education

Model D: Association between recalled early non-fatal suicidality, race and year of birth, adjusted for adult family income only

* Statistically significant 